\title{
GCSE project for distance evaluation of knowledge in French foreign language
}

\author{
R. Bedanokova and Ph. Teutsch \\ LIUM - Université du Maine \\ 72085 LE MANS Cedex 9, France \\ E-mail : Philippe.Teutsch@lium.univ-lemans.fr
}

\begin{abstract}
In this paper we present the GCSE project that has as its aim the creation of a system for distance evaluation of the knowledge in the French foreign language. The main objective of the system is to put at the disposal of pupils, from a distance, exam-type questions with correction and automatic evaluation. Our main interest was focused on the evaluation of the student's written response.

The design of a test environment for languages is a difficult field to manage: the modelling of the linguistic field and the treatment of language are badly understood, the learning of the language is relatively contextual. Additionally the computer creates a particular didactic situation which is unfamiliar.

We discuss the problems of putting the evaluation of student's knowledge into a computer context and present the iterative design process of the system that helps to overcome these problems.
\end{abstract}

\section{Keywords}

Automatic evaluation, Self-learning, Language-learning assessment 


\section{INTRODUCTION}

The Interactive Learning Environments (ILE) greatly interests foreign language teachers for their capabilities to create interactive environments of learning.

What do new technologies add to the evaluation sequences of the student's knowledge? They enrich the learning environment; they offer the possibility of different forms of representation of the task-based testing material: combining text with multimedia capabilities.

Today the computer is considered to be a partner in the whole process of the learning of languages (Chanier 1991). From the trend of learner-oriented approach, the language teachers seek to put the student into a situation of real communication and to enable him to analyse his own efforts (Narcy 1990). The tools of autoevaluation and assisted auto-orientation become in this context as important as all the others (Teutsch, Vivet 1993).

The main difficulties that we encounter in this perspective are the following:

- the use of computers as a teaching aid has had profound influence on the situation of learning but this has not been fully researched (Vivet 1991) ;

- the problems of good integration of the designed software with different teaching methods into a coherent teaching process ;

- we cannot preview the exact use that will be made of the system.

This is the context in which we have designed a GCSE server (the abbreviation of the General Certificate of Secondary Education), the system of evaluation of knowledge in a French foreign language targeted at young English people.

\section{DESCRIPTION OF THE GCSE PROJECT}

The aim of the GCSE project is to make available to young Anglophones the means of the preparation for the GCSE exam in a French foreign language, as a support of individualised evaluation. One of the ideas of the GCSE project is the use of new technologies to bridge the gap between students learning French and the real users of the French language, in other words, put at their disposal the means of direct contact with French tutors.

The main features of the GCSE server are: WWW-based intelligent analysis of student solutions, advanced testing and debugging facilities.

The concept of the GCSE server has been guided by MARPLE, a system of evaluation in English intended for professional training (Teutsch, 1994). The multidisciplinary team created around the MARPLE project has defined a tool for formal specification of the "Situation of Knowledge Evaluation » (Teutsch 1996, ITS). It is the meeting point between the computer specification of the system and the analysis of the didactic situation. 


\section{The context of the project}

Since 1986, the diploma awarded at the end of the first cycle of secondary education in Great Britain has been GCSE: the General Certificate of Secondary Education. It is taken in various subjects including a foreign language (French, German, Spanish, Japanese, Chinese, Italian). An exam in a foreign language will become compulsory for all those beginning secondary education in 1998 .

The exam can be taken in two levels: basic, obligatory for all who take a GCSE exam in a foreign language, and higher level, where the student has a choice of either passing the whole exam or only parts of it. Our system presents the user with a choice of these levels of functioning which reflects the exam options.

\section{The aims of the project}

The main functions of GCSE system are to validate certain individual skills in a foreign language - reading and listening comprehension, writing and speaking ; and to help the student realise his capabilities at the end of each session of evaluation of these skills. The role of the system is not only to validate his level, to underline his errors but also to give him a knowledge about his strong and weak points. The situation of evaluation that the student is put into by the GCSE server directly involves him in self-appraisal and self-learning. It helps them to confront and compare their capabilities with the standard.

Through exercises of the test situations and through linguistic exchanges betv:een the system and the stude 7 the latter develops analytic abilities. He also learns how to master his mistakes, io assess and explain them, and to solve them. It is the student who is in control of the pedagogical sequence, it is he who decides what is the next step. The role of the teacher is to help the student to work in this direction and to overcome his problems. Under these conditions, the fact that the teacher has at his disposal a means of supporting his work of evaluation, he needs no longer mark papers but may become a directly accessible tutor, as the GCSE server can not replace the teacher in more individual consultation or in making decisions concerning the student's needs.

\section{The problematic of the question}

In our work we were interested in overcoming the problems that are encountered by the designers of CALL (Computer Assisted Language Learning) systems and in investigating in the following problematic:

- representation of the knowledge

- the method of the system design.

The use of the computer aid in an educational process requires the formal representation of the knowledge of the domain. But the problems that arise in attempting to comprehend the language teaching make it very difficult.

The existing systems lack expertise in the didactic situation of their use. Those systems are only oriented towards grammatical and linguistic knowledge (Yazdani 1989) and do not take into account the cognitive process developed by the student. The result is limited to dull structural exercises with limited aim (Swartz\&Yazdani 1991), the analysis of responses is relatively poor. 
In terms of evaluation of the system, «English Tutor» (Fum 1991) has some advantages in applying strategies of analysis: the error response activates the creation by the system of number of hypotheses on the certain knowledge of a student that are taken into account in the choice of next set of exercises.

The research work on the development of such systems (representation of the knowledge of the domain, architecture of the system, user interface) has to be built around the analysis of where the system supports the teacher in the process of evaluation and of the analysis of the aspects of its real use.

Our method is to create an interactive linguistic, cultural and didactic area, where the student is going to progress, discover for himself his abilities; the system is designed to increase his performance. We have designed the interactive environment in a style which is also characteristic of the situation of its real use. The system benefits the main guidelines of the GCSE exam: communicative approach, tolerance of mistakes, a learner-oriented approach, use of real documents. To achieve this, we have used the iterative method for the conception of the system.

One of the objectives of our work is to present the specification of the methods of conception that can be generalised and reused in other situations.

\section{SITUATION OF KNOWLEDGE EVALUATION}

This model consists of three main classes that describe the elements of the interaction and their features.

- The description of the teaching material (sequence of courses, grammar material, vocabulary and especially the test situations) together with the cultural topics.

- The description of the support to the process of evaluation seen from its objectives, description of the activity proposed by the test and detailed reference to the material to work on. Each question corresponds to the « Model of Analysis » which defines the anticipated student's input and the comments to his errors.

- The description of the mode of interaction as a support to the presentation (text, sound, image) and the mode of response, proposed to the user. In the evaluation of the student's output the mode of interaction has to be taken into consideration as it influences more or less the student's response.

This model of "Situation of Knowledge Evaluation » helps to adapt at the same time the design according to the principles of modular architecture and to the iterative method of designing. In the dialogue between specialists in didactic and computer sciences, the initial design hypothesis is modified by experimentation. 


\section{THE ITERATIVE METHOD OF THE SYSTEM DESIGN}

The conception of the GCSE helped to overcome these problems by using the iterative method of conception that consists in creation of prototypes taking into consideration the objectives and constrains of activities in both fields: creating an interactive system and studying the didactic situation of evaluation (Teutsch 1994).

Cumming and Self (1990) showed that the "front approach » in the conception of ITS requires an extremely detailed representation of knowledge. As a consequence the encountered difficulties prevent the creation of usable systems.

For GSCE, the first step was to define and design the interactive environment proposed to the student, that is based on the specification of the situation of evaluation; and the second step was concerned with the studies and designing of the linguistic contents and test material.

Thus, in designing the GCSE system, we have followed the stages of:

1. Preliminary studies. Studying the user together with the context of the use of the system, the first specifications of the situation of evaluation.

2. Creation of a model of a system. Specification of the interactive environment seen from a user interface, designing the system architecture. On this stage we are concerned with aspects of interaction that are created by the situation of evaluation.

3. Development of the system. Designing the linguistic contents of the system: the specification of the linguistic knowledge; definition of the test situations, making the hypothesis of the student's responses. On this stage we are mainly concerned with adapting the test material to the peculiarities of the system usage and the difficulties that the student may encounter.

4. Experimentation. On this stage our objective is to validate the proposed situations and to learn the linguistic behaviour of the students in the situation of real use.

5. Creating a new prototype. The evaluation of results of real usage requires incorporating the design changes into a model that we test on the users again.

The use of this spiral method in designing of an interactive system allows us to propose the skeleton of the architecture of the system and then to refine gradually its functional and communicative aspects.

\section{THE ENVIRONMENT OF EVALUATION}

As we have mentioned earlier, the test material proposed by GCSE system is designed to follow the objectives of GCSE exam in a French language and is based on the real life situations and are supported by authentic documents (brochures, posters and signs).

The system presents all the situations of evaluation in two major axes: to enable a student to be evaluated in a certain skill in a foreign language; to enable a student to get evaluated in a foundation or higher level.

All the presented situations can be tried in two test modes: 
1. Exam mode, which places the user in an exam situation with an access to the answers only at the end of the session.

2. Training mode, in which answers and explanations are given during the test.

Each of these modes gives the possibility of being evaluated in four skills: listening, speaking, reading, writing that evaluate four respective communication skills of the students. At present the software has only been developed for two: reading and listening.

Listening: the system tests listening comprehension skills using multimedia facilities to present audio material, the recorded documents specially made for the exam.

Reading and writing: the system tests these skills by evaluating in a synchronous way the answers through writing in input fields, checkbox or map-images.

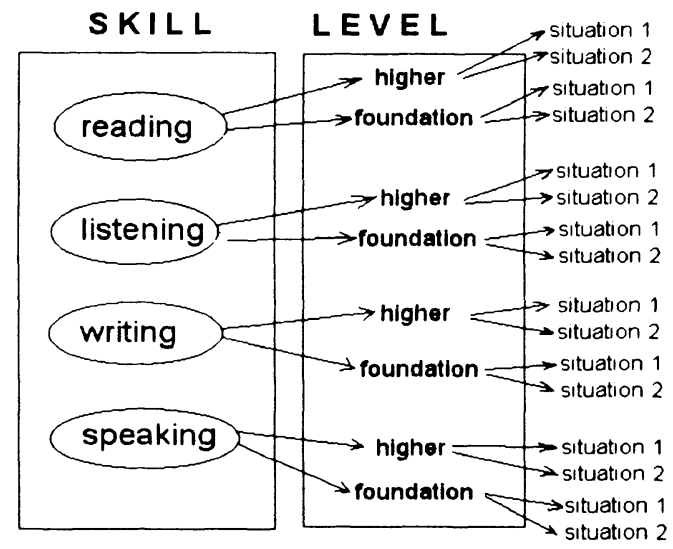

Figure 1. The elements of GCSE system.

In figure 1 we present the elements of the system. At the beginning of each session of evaluation the student is free to choose the mode of work (exam or training), the skill to be evaluated (reading, listening, writing or speaking) and, finally, the level of the competence (foundation or higher). Each situation (situation 1 or situation 2) comprises a set of questions (from 3 to 7 for each level), dealing with different subjects. For example, while travelling to France the student finds himself on the ferry, in the shop, where he has to put the fight labels to the items of clothes, at a restaurant, in the tourist office, etc.

The representations of the test material is chosen for its explicative power, communicability, simplicity and for facility of execution. The advantage of the use of such a system is that the student makes free choices in mode, skill or level over and over again, is free to control the session of evaluation. They also can modify their responses and check them again. The material is presented in a way that allows the student to progress from easier questions, some in mother tongue, at a 
allows the student to progress from easier questions, some in mother tongue, at a foundation level, to more difficult questions at a higher level. They plan themselves the amount of time spent on the preparation for the exam. This is not possible in a usual situation with a single available teacher for the whole group.

In the training mode, if a student would like to see the corrections to his answers, the system launches the window of comments. In the exam mode the student doesn't get the synchronous evaluation. He can have his results only at end of the session. Figure 2 represents respectively the copy of the page of one of the situations and the window of corrections. The topic of evaluation concerns the trip of one of the main characters of the GCSE situations - a French girl Sandrine.

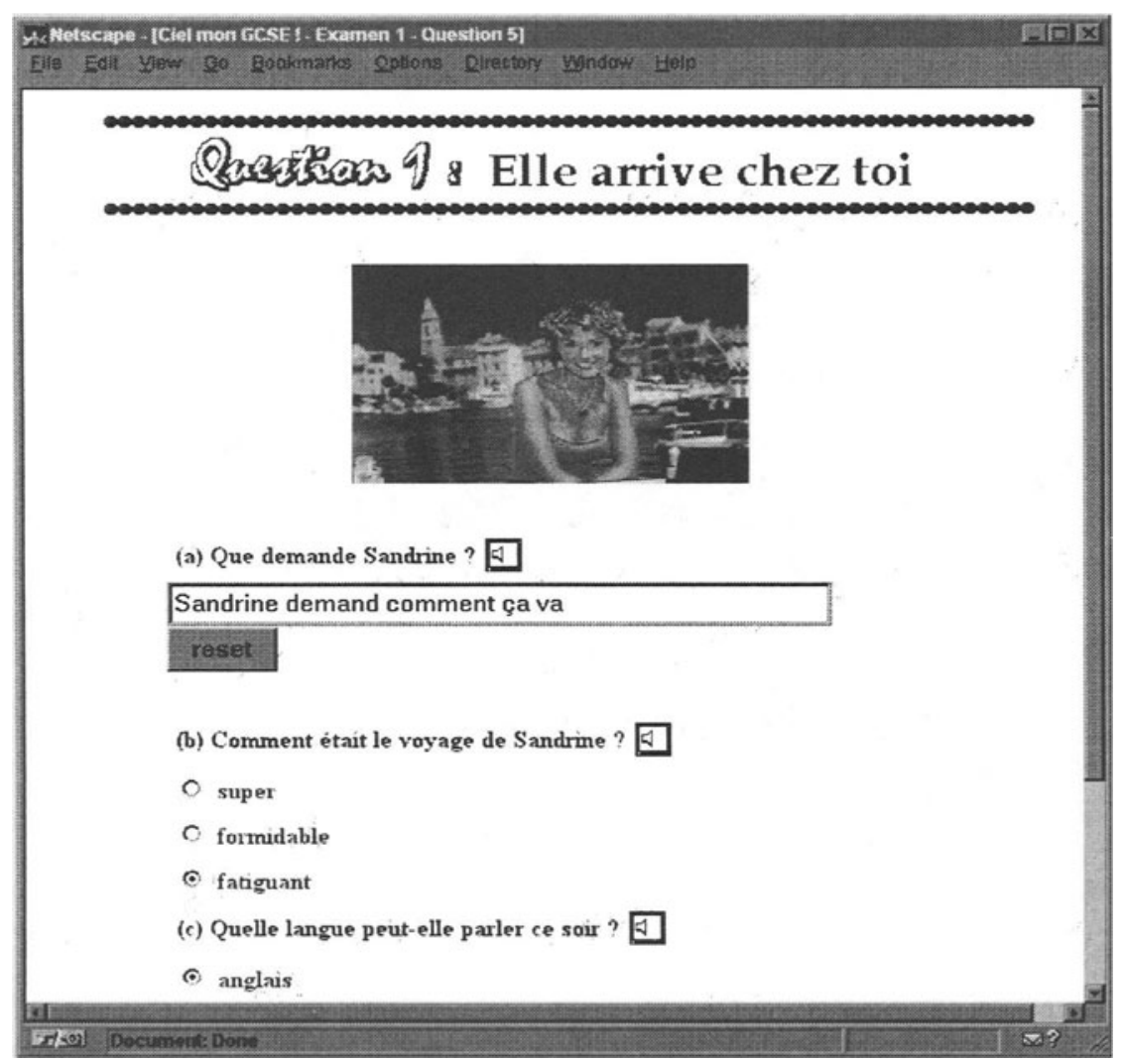

Figure 2 (a).Situation of evaluation in listening comprehension/foundation level. 


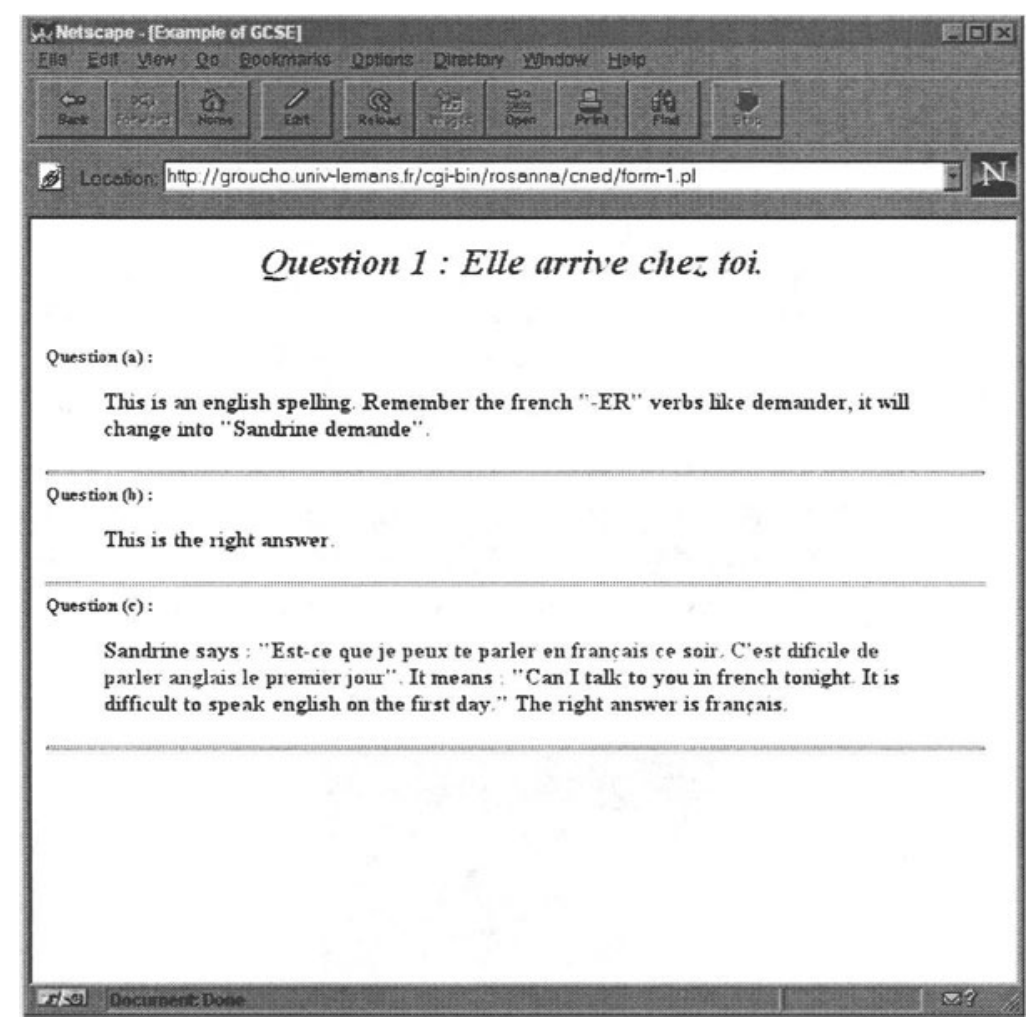

Figure 2 (b). Window of correction corresponding to student's responses.

\section{EVALUATION OF STUDENT RESPONSES}

In the designing of the GCSE server our interest was mainly focused on the WWW-based intelligent analysis of the student's input data, on the measuring of individual performance with a set of tasks in a specific situation. While creating the hypothesis on the student's responses, we took into consideration the frequent errors made by Anglophones in the French foreign language.

In our case we are dealing with the functional, linguistic (grammar, morphology, syntax), lexical and cultural knowledge of the student. It might contain descriptions, expressed as linguistic frames, schemes, the meanings of words and the types of the associations between the lexical units in mother-tongue and target language the student might have built. Therefore this analyser comprises many different levels of analysis.

The basis of analysis of the written response of the system is the comparison of the student's answer against the tree of possibilities foreseen by the teachers. This 
tree is deduced from a whole range of possible responses. Each response model describes an envisaged answer and incorporates into it correct and incorrect answers for each term. The analyser exploits permanent syntax, spelling, grammar, lists of equivalent terms as well as detectable mistakes and their type.

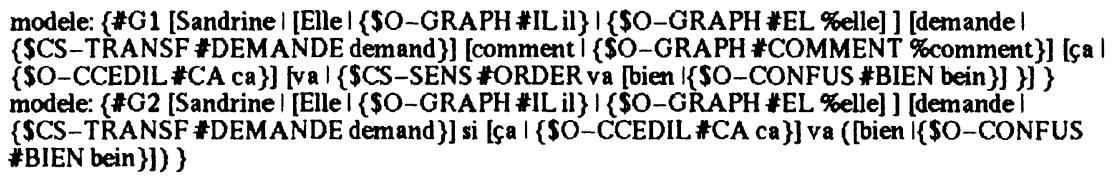

Figure 3. « Analysis chart » in GCSE.

Each question corresponds to the " analysis chart " (figure 3) which consists of the response models, equivalences of various forms of words or their synonyms and comments to be shown to the student in the function of his response :

- The syntactic response model. The models present both correct and incorrect answers using the equivalences for some words or groups of words where necessary. For each type of the error a special code is used, which is also incorporated in this model. The programme refers to the list of types of errors to decode it and adds this information to the trace of the student's session.

- Equivalence is used where necessary to mark the fact of equivalence between words or phrases in the treatment of the student response.

- Comments. To each anticipated response the system can give a comment in the mother-tongue. It allows a student to be informed about his successes or errors.

For each student's answer the system compares it word by word with the response models in the corresponding « analysis chart ».

Together with the evaluation the system aims at the qualitative and quantitative improvement in foreign language competence. The comment material relies on the principle that students must « learn from their mistakes ». But also we can't forget about the fact that young English people might have problems in understanding the 
grammar explanations in the comments to errors as they are often not taught much about the grammar structure of their mother-tongue.

The system uses the direct remediation in most of the cases: a direct corrective statement, dealing with the knowledge that the student should have rather than the buggy knowledge he does, in fact, have. This choice is primarily made in the case of the wrong translation of words when the buggy knowledge is considered as a mere factual error which does not indicate a misconception.

For example, the error in grammar «ils parle » is corrected with the following explanation: "-ER verbs like parler change their endings for each person: je parle - I speak, tu parles - you speak, ils parlent - they speak ».

The error of the type "bon idée » is corrected with the following explanation : " idée is a feminine word so the adjective describing it needs to be in a feminine form too : une bonne idée ». Also the correction of errors consists of material that suggest the ways of associating the words (memo-rules). If an error is made in the spelling of the word "comment » in the phrase "Comment ça va? " ( How are you?»), the system suggests it is associated with another English word : " Think about the English word comment, it is just the same spelling ".

In the case where there are errors in grammar or spelling, the explanations of the rules are given. In the cases where the system cannot interpret a student's input, it informs the user that his or her response cannot be evaluated and collects these unforeseen responses that will be treated and added to " analysis chart ".

\section{CONCLUSION}

The GCSE server presents a system of the evaluation of student's knowledge in French and a tool for preparing for the GCSE exam. In the system design an effort was made to transfer pedagogic knowledge to the creation of a computerised environment.

A redefinition of roles takes place with the appearance of new actor - computer technology in the teacher-student relationship. How exactly does the server replace the teacher in the evaluation process? In organising the evaluation environment; in providing the language data for the learners; in providing appraising feedback to the learners. But the GCSE server does not make decisions concerning their individual needs. It is the learners who make this decision for themselves. How does the server support the learner's activity in the evaluation process? By building the conditions for their autonomous work, benefiting the gradual process of constructing knowledge about self-knowledge, by allowing them to check and govern their own output and learn from their mistakes.

The specification of the "Situation of Knowledge Evaluation " and the iterative method of the designing enabled us to create a system that meets all the requirements of its use. The flexibility of the system allows the experiment results to be incorporated in the response models at each step of this spiral process. 


\section{REFERENCES}

Chanier Th. (1991) Perspectives de l'apport de l'EIAO dans l'apprentissage des langues étrangères. $4^{\text {zme }}$ Assises de l'IA et de la Formation, Paris.

Cumming G. and Self J.(1990) Intelligent Educational Systems: Identifying and Decoupling the Conversational Levels. Instructional Science, 1-17, $n^{\circ} 19$.

Fum D., Giandgrandi P. and Tasso C. (1991) The Use of Explanation-based Learning for Modelling Student Behavior in Foreign Language Tutoring, in Swartz \& Yazdani 1991.

Narcy J.P. (1990) Apprendre une Langue Etrangère, Les Editions d'Organisation, Paris.

Swartz and Yazdani (1991) Intelligent Tutoring Systems for Second-Language learning, the Bridge to International Communication, Springer Verlag.

Teutsch Ph. and Vivet M. (1993) Interaction Issues in Computer Assisted Language Learning Systems. International Conference on Computers in Education, 144-149, Taiwan.

Teutsch Ph. (1994) Environments Interactifs et Langue Etrangères, MARPLE: système d'évaluation et de suivi de formation. Thèse de l'Université du Maine, Le Mans.

Teutsch Ph. (1996) Un modèle de Situation d'Evaluation pour le Suivi de Formation en Langue Etrangère. ITS'96 Third International Conference on Intelligent Tutoring Systems, 315-323, Montréal.

Vivet M. (1991) Usage des tuteurs intelligents: prise en compte du contexte, rôle du maître. $2^{\text {zme }}$ Journées EIAO, 239-246, Cachan.

Yazdany M. (1989) An Artificial Intelligence Approach to Second Language Teaching, $2^{\text {nd }}$ ICCAL (ed. Springer Verlag), Dallas.

\section{BIOGRAPHIES}

Rousanna Bedanokova is post-graduate student and Philippe Teutsch is researcher in computer science laboratory of the Université du Maine (LIUM, Le Mans, France). Both study the design of interactive learning environments and the use of such systems in distance learning situation, especially in the language learning domain. Their actual research focuses in the use of knowledge of language teachers to make an intelligent evaluation of language ability, and to give advice about further training. 